\title{
Knowledge on vitamin A rich foods among mothers of preschool children in Nepal: Impacts on public health and policy concerns
}

\author{
Azizur Rahman ${ }^{1}$, Mahesh Sapkota ${ }^{2}$ \\ ${ }^{1}$ School of Computing and Mathematics, Charles Sturt University, WaggaWagga, Australia \\ ${ }^{2}$ School of Public Health, Chonbuk National University, Jeonju, South Korea
}

Email address:

azrahman@csu.edu.au (A. Rahman), sapkotamahesh3@gmail.com(M. Sapkota)

To cite this article:

Azizur Rahman, Mahesh Sapkota. Knowledge on Vitamin A Rich Foods among Mothers of Preschool Children in Nepal: Impacts on Public Health and Policy Concerns. Science Journal of Public Health. Vol. 2, No. 4, 2014, pp. 316-322.

doi: $10.11648 /$ j.sjph.20140204.22

\begin{abstract}
This study investigated the association of some socio-demographic, attitude, service availability and info-communication factors with the knowledge on vitamin A rich foods among mothers of preschool children in Nepal with its impacts on public health and policy concerns. The analyses demonstrated that about $71 \%$ of mothers were the Hindus ethnic group and $67 \%$ lived in nuclear family. A half of the child bearing aged mothers $(51 \%)$ had higher secondary education with nearly $91 \%$ of the mothers were aware of vitamin A rich foods. A majority of mothers (53\%) were in workforce and $65 \%$ of them had monthly family income above 10,000 Rupees with a good economic status. Almost $91 \%$ of the respondents' mothers grew vitamin A rich foods in their kitchen gardens and took it in their daily meal as diet. An estimate of $93 \%$ mothers attendeda health centre with their children during the vitamin A supplementation campaign. About $79 \%$ mothers reported that they knew about the first visible symptoms of vitamin A deficiency disorder (VADD) and 95\% mothers knew about the night blindness. The findings revealed that in Nepal knowledge on vitamin A rich foods among mother's of pre-school children is widely increasing, and in a particular community VADD has estimated as $9 \%$ while at the national level its real magnitude is still high at $24 \%$. When the prevalence of VADD has been in a decreasing trend at local level communities then the overall rate also drops at the national level. Bivariate analysis showed that the three selected factors such as mother's education levels, mother's occupations, and monthly family income were significantly and positively associated with the mother's knowledge on vitamin A rich foods in diet, VADD curable and include green leafy vegetable and yellow fruits in diet.As these significant factors are directly influencing the level of awareness and practice of consuming vitamin A rich foods, efforts from the government and non-government organisations are needed to improve the overall conditions of mothers and allied public policy concerns in Nepal.
\end{abstract}

Keywords: Vitamin A Deficiency, Information Education and Communication, Dark Green Leafy Vegetables, Socio-Demographic Factors, Knowledge on Vitamin A, Nepal

\section{Introduction}

Vitamin A deficiency (VAD) is a major public health problem in more than half of all countries in the world, especially countries in Africa and South-East Asia. Mostly young children and pregnant women in low-income countries are severely affected by VAD. It is identified as the leading cause of preventable blindness in children and increases the risk of disease and death from severe infections. The 1990 World Summit for Children called for the elimination of vitamin A deficiency by the end of the decade (James et al., 2000). In 1995, over 3 million children were estimated to exhibit clinical or severe vitamin A deficiency(ACC/SCN, 1997). Severe vitamin A deficiency is on the decline in all regions. However, subclinical vitamin A deficiency still affects between 140 and 250 million preschool children in developing countries, and is associated with high rates of morbidity and mortality (WHO, 1996; ACC/SCN, 1997). In Asia, vitamin A deficiency is common in pregnant and lactating women(Bloem et al., 1995; Katz et al., 1995).Recent 
surveys indicate that night blindness from vitamin A deficiency is common among pregnant women in India, Indonesia, Bangladesh, Nepal and elsewhere, particularly during the latter half of pregnancy Katz et al., 1995; Christian et al., 1998).Most surveys reveal rates of night blindness of $10 \%$ or more during pregnancy in populations in which the children are commonly deficient. Vitamin A deficiency disorder affects large numbers of young children and women of childbearing age throughout the developing world (James et al., 2000).

Childhood and maternal underweight and health related nutritional deficiencies are the greatest risk factors among several main health concerns that affect people's health and infectious and chronic diseases in the world (WHO, 2002; Rahman and Harding, 2011; Sally et a., 2012; Rahman and Harding, 2013; Megabiaw and Rahman, 2013; Rahman and Kuddus, 2014), particularly in south-east Asia (Rahman and Chowdhury, 2007; Rahman et. el., 2008, 2009; Rahman and Biswas, 2009). For an example, Rahman and colleagues have been identified four groups of significant risk factors for nutritional status of under-5 children for developing countries. Nepal is one of the poorest developing countries in the world; more than one-fourth of its population is living below the poverty line (UNICEF, 1997; NDHS, 2011).Statistics on health related factors such as education, income, expenditure, social participation and behaviours, welfare distributions etc are important for policy makers and program managers at local and national levels to gauge the health and nutrition status and overall well-being of the population (Rahman et al., 2010, 2012; Rahman and Harding, 2014). Currently two-thirds of women in Nepal (67 percent) are literate, which represents an increase from the 2006 figure of 55 percent. The level of literacy is much higher among women age 15-19 than among women in other age groups. This suggests that younger mothers have more knowledge than older mothers. Marriage occurs relatively early in Nepal; among women age $15-49,55$ percent were married by age 18 , and 74 percent were married by age 20years (NDHS, 2011).

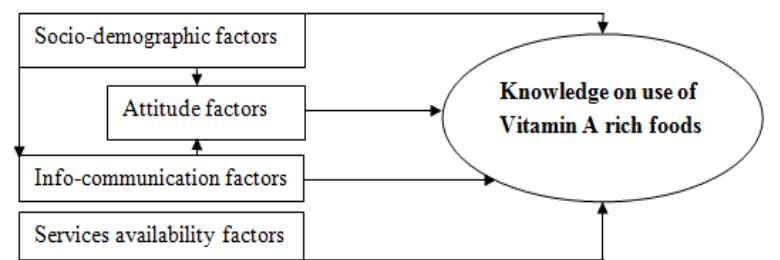

Figure 1. A conceptual framework to research on knowledge of vitamin A rich foods among mothers of preschool children in Nepal

Woman's nutritional status and knowledge on foods have important implications for her health and for the health of her children (de Pee et al., 1995).A conceptual framework to research on knowledge of vitamin A rich foods among mothers is depicted in Fig. 1. According to this framework, knowledge on vitamin A rich foods among mothers of preschool children is proximately determined by different groups of factors such as socio-demographic, attitude, service availability and info-communication related factors of mothers. Although services availability factors have independent effects to knowledge on use of vitamin A reach foods, the socio-demographic factors influence both the attitude and info-communication factors. Moreover, the info-communication factors affect the attitude factors of mothers.

The key aims of this study are to examine the linkage between some selected socio-demographic, attitude, service availability and info-communication factors and the knowledge on vitamin A rich foods among mothers of preschool children in Nepal, and then to distinguish its impacts on public health and policy issues in the country.

The remainder of the paper is organised as below. Section 2 provides information about data and research methods. Section 3 presents descriptive results of the selected variables. Section 4 reports on the results from bivariate analyses. And Section 5 offers critical discussions on significant findings with the concluding remarks.

\section{Data and Methods}

The data utilized for this research were from a scientifically structured field-study that was designed to collect knowledge on vitamin A rich foods among mothers of under-5 children residing at the local Ward no. 14 in the Rupandehi District of Nepal. The target population of the field-study was all the mothers aged 18-40 years and with having preschool children on the study area. The inclusion criteria of respondent were that a mother must showed interest for the interview and has at least one under-5 years aged child but not more than a total four children. A mother suffering from chronic alignment or who is mentally retarded or not willing to participate in interview was considered as ineligible for the survey.

A total of 121 women were sampled during the period from the $1^{\text {st }}$ of August to the $31^{\text {st }}$ of December in 2011. This purposive non-randomized cross-sectional survey provides a comprehensive history for vitamin A related knowledge and activities which those mothers have been practiced in that community. A pretested semi-structured questionnaire was used to collect the data. All completed questionnaires were thoroughly checked and then data were entered on the computer programs SPSS. As the primary objective of this research is to assess the knowledge on vitamin A-rich foods among the mothers of preschool children, it is fairly a descriptive research and all statistical analyses have been carried out using the SPSS for Windows software (version 11.5).

\section{Results}

The characteristics of the study's mother's having preschool children are summarized in Table 1.A socio-demographic profile of the study population shows that in Butwal-14, Tamnagar, Nepal, nearly forty three percent (52) mothers were aged 28-32 years and only about 
eleven percent (13) mothers were less than 23 years. More than seventy one percent (86) women were Hindu which is followed by Buddhist about twenty nine percent (35). Likewise fifty one percent (62) and twenty eight percent (34) women had higher secondary level and secondary level education respectively. Two third of mothers (81) were lived in nuclear family, and more than half of the respondents were employed with forty three percent as a service holder. Sixty five percent of mothers (79)have had a monthly family income of more than 10,000 rupees.

In term of attitude factors, almost ninety one percent (110) respondent mothers grew vitamin A rich foods in their kitchen garden. Likewise ninety six percent (116) respondents provide vitamin A rich foods to their children, and ninety three percent (113) women attend health center with their children for heath checkup.

Table 1. Socio-demographic, attitude, info-communication and services availability characteristics of respondents' mothers aged 18-40 years in Nepal, 2011

\begin{tabular}{|c|c|c|}
\hline Characteristic and categories & $\begin{array}{l}\text { No. of } \\
\text { respondent }^{\text {a }}\end{array}$ & $\begin{array}{l}\text { Percentage of } \\
\text { respondent }\end{array}$ \\
\hline \multicolumn{3}{|l|}{ Socio-demographic } \\
\hline \multicolumn{3}{|l|}{ Age of respondents (years) } \\
\hline$<23$ & 13 & 10.7 \\
\hline $23-27$ & 42 & 34.8 \\
\hline $28-32$ & 52 & 42.9 \\
\hline$>33$ & 14 & 11.6 \\
\hline \multicolumn{3}{|l|}{ Religion } \\
\hline Hindu & 86 & 71.1 \\
\hline Buddhist & 35 & 28.9 \\
\hline \multicolumn{3}{|l|}{ Education } \\
\hline Illiterate & 11 & 9.1 \\
\hline Primary & 14 & 11.6 \\
\hline Secondary & 34 & 28.1 \\
\hline Higher Secondary & 62 & 51.2 \\
\hline \multicolumn{3}{|l|}{ Respondent family types } \\
\hline Nuclear & 81 & 66.9 \\
\hline Joint & 40 & 33.1 \\
\hline \multicolumn{3}{|l|}{ Respondents family occupation } \\
\hline Housewife & 56 & 46.3 \\
\hline Service holder & 52 & 43.0 \\
\hline Labourer and others & 12 & 10.8 \\
\hline \multicolumn{3}{|l|}{ Monthly family income in (Rs) } \\
\hline$<8001$ & 20 & 16.5 \\
\hline 8001 to 10000 & 22 & 18.2 \\
\hline $10000+$ & 79 & 65.3 \\
\hline \multicolumn{3}{|l|}{ Attitude } \\
\hline \multicolumn{3}{|l|}{ Grow vitamin A rich foods } \\
\hline Yes & 110 & 90.9 \\
\hline No & 11 & 9.1 \\
\hline \multicolumn{3}{|l|}{ Feeding vitamin A rich foods } \\
\hline Yes & 116 & 95.9 \\
\hline No & 5 & 4.1 \\
\hline \multicolumn{3}{|l|}{ Attending health centre. } \\
\hline Yes & 113 & 93.4 \\
\hline No & 8 & 6.6 \\
\hline \multicolumn{3}{|l|}{ Service availability } \\
\hline \multicolumn{3}{|l|}{ Availability of health complex } \\
\hline Yes & 118 & 97.5 \\
\hline No & 3 & 2.5 \\
\hline \multicolumn{3}{|l|}{ Distance of health complex } \\
\hline$<1 \mathrm{~km}$ & 46 & 38 \\
\hline $2-4 \mathrm{~km}$ & 75 & 62 \\
\hline
\end{tabular}

\begin{tabular}{|c|c|c|}
\hline Characteristic and categories & $\begin{array}{l}\text { No. of } \\
\text { respondent }^{\text {a }}\end{array}$ & $\begin{array}{l}\text { Percentage of } \\
\text { respondent }\end{array}$ \\
\hline \multicolumn{3}{|l|}{ Attending health complex. } \\
\hline Yes & 118 & 97.5 \\
\hline No & 3 & 2.5 \\
\hline \multicolumn{3}{|l|}{$\begin{array}{l}\text { Free medicine supply and health } \\
\text { support. }\end{array}$} \\
\hline Yes & 118 & 97.5 \\
\hline No & 3 & 2.5 \\
\hline \multicolumn{3}{|l|}{ Info-communication } \\
\hline \multicolumn{3}{|l|}{ Source of information } \\
\hline Radio/TV & 31 & 25.6 \\
\hline Health workers & 62 & 51.3 \\
\hline Poster pamphlets & 28 & 23.1 \\
\hline \multicolumn{3}{|l|}{ Information from health campaign } \\
\hline Yes & 78 & 64.5 \\
\hline No & 43 & 35.5 \\
\hline \multicolumn{3}{|l|}{$\begin{array}{l}\text { Information from families and } \\
\text { friends. }\end{array}$} \\
\hline Yes & 110 & 97.9 \\
\hline No & 11 & 9.1 \\
\hline \multicolumn{3}{|l|}{ Know about first visible symptoms } \\
\hline Yes & 95 & 78.5 \\
\hline No & 26 & 21.5 \\
\hline \multicolumn{3}{|l|}{$\begin{array}{l}\text { Symptoms of vitamin A deficiency } \\
(* n=95)\end{array}$} \\
\hline Night blindness & 90 & 94.7 \\
\hline Low immunity & 5 & 5.3 \\
\hline \multicolumn{3}{|l|}{$\begin{array}{l}\text { Knowledge on importance of } \\
\text { vitamin A rich foods }\end{array}$} \\
\hline Yes & 101 & 83.5 \\
\hline No & 20 & 16.5 \\
\hline \multicolumn{3}{|l|}{$\begin{array}{l}\text { Green leafy vegetables and yellow } \\
\text { fruits }\end{array}$} \\
\hline Yes & 110 & 90.9 \\
\hline No & 11 & 9.1 \\
\hline \multicolumn{3}{|l|}{$\begin{array}{l}\text { Vitamin A deficiency disorder } \\
\text { curability. }\end{array}$} \\
\hline Yes & 110 & 90.9 \\
\hline No & 11 & 9.1 \\
\hline \multicolumn{3}{|l|}{$\begin{array}{l}\text { Vitamin A deficiency disorder } \\
\text { preventability. }\end{array}$} \\
\hline Yes & 38 & 31.4 \\
\hline No & 83 & 68.6 \\
\hline
\end{tabular}

*Total number of children may differ due to missing data.

More than ninety seven percent (118) mothers knew about the availability of health complex in their community for health checkup while sixty two percent (75) of them stayed in between $2-4 \mathrm{~km}$ distance. Ninety seven percent (118) mothers attend health service from health complex, and they also receive free medicine and health support from health worker for any kind of health facilities they required. Besides this, more than half of the mothers(62) got information from health workers while a quarter of them got information via Radio/TV. Likewise sixty four percent mothers (78) got information from health campaign in their community and ninety eight percent (110) got information from families and friends. More than three-fourth of mothers (95) are aware about the first visible symptoms with ninety mothers told night blindness is the first visible symptoms. Additionally, more than eighty three percent mothers (101) had knowledge on importance of vitamin A rich foods, and nine out of each ten mothers had knowledge 
to included green leafy vegetable and yellow fruits in diet. Finally, ninety one percent mothers(110) knew vitamin A deficiency disordered can be cured, whereas more than two third of mothers (83) didn't agree that it can be preventable.

\section{Bivariate Analysis}

Table 2 presents the association of mother's education levels with three selected significant factors such as mother's knowledge on vitamin A rich foods in diet, Vitamin A deficiency disorder curable and Include green leafy vegetable and yellow fruits in diet. Results reveal that there is a significant relationship between the mother's education levels and knowledge on vitamin A rich foods in diet. Out of 11 illiterate mothers, 7 mothers liked to give vitamin A rich foods and 4 mothers had no idea to add vitamin A rich foods in the diet. Approximately $10.7 \%$ mothers who had a primary education liked to add vitamin A rich foods in the diet and only $0.8 \%$ had no knowledge to include vitamin A rich foods in the diet. It is apparent that increasing level of mother's education has positive association with the knowledge on vitamin A rich foods in diet (see, Fig. 2). All of the mothers who had a secondary and higher secondary levels education have knowledge to include vitamin A rich foods in the diet.

Mother's education also shows significant positive relationship with the knowledge on vitamin Adeficiency disorder (VADD) curable and knowledge on to include green leafy vegetable and yellow fruits in diet. About 9.2\% mothers, who had primary education, knew about VADD curability and almost all of the mothers who had a secondary to higher secondary levels education have knowledge on this VADD issue. Besides this, all mothers from illiterate, secondary and higher secondary levels education include green leafy vegetable and yellow fruits in diet although illiterate mothers may not know about the positive effect of green leafy vegetable and yellow fruitsin diet. However, only $0.8 \%$ of primary educated mothers have indicated that they had no knowledge to include green leafy vegetable and yellow fruits in diet (Fig. 2).

Table 2. Association of mother's education levels with knowledge on vitamin A rich foods in diet, Vitamin A deficiency disorder curable and Include green leafy vegetable and yellow fruits in diet $(2011, n=121)$

\begin{tabular}{|c|c|c|c|c|c|}
\hline \multirow{2}{*}{\multicolumn{2}{|c|}{$\begin{array}{l}\text { Variables with } \\
\text { categories }\end{array}$}} & \multicolumn{4}{|c|}{ Mothers' education levels } \\
\hline & & \multirow{2}{*}{$\begin{array}{l}\text { Illiterate } \\
7\end{array}$} & \multirow{2}{*}{$\begin{array}{l}\text { Primary } \\
13\end{array}$} & \multirow{2}{*}{$\begin{array}{l}\text { Secondary } \\
34\end{array}$} & \multirow{2}{*}{$\begin{array}{l}\begin{array}{l}\text { Higher } \\
\text { secondary }\end{array} \\
62\end{array}$} \\
\hline Vitamin A & Yes & & & & \\
\hline $\begin{array}{l}\text { rich foods } \\
\text { in diet* }\end{array}$ & No & 4 & 1 & 0 & 0 \\
\hline $\begin{array}{l}\text { Vitamin A } \\
\text { deficiency }\end{array}$ & Yes & 5 & 11 & 32 & 62 \\
\hline $\begin{array}{l}\text { disorder } \\
\text { curable* }\end{array}$ & No & 6 & 3 & 2 & 0 \\
\hline $\begin{array}{l}\text { Include } \\
\text { green leafy } \\
\text { vegetable }\end{array}$ & Yes & 11 & 13 & 34 & 62 \\
\hline $\begin{array}{l}\text { and yellow } \\
\text { fruits in } \\
\text { diet* }\end{array}$ & No & 0 & 1 & 0 & 0 \\
\hline
\end{tabular}

$* \mathrm{p}<0.01$
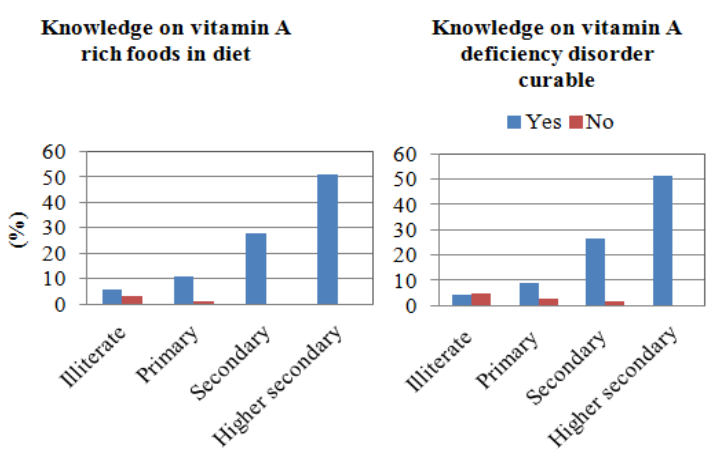

Knowledge on including green leafy vegetable and yellow fruits in diet

Education Level

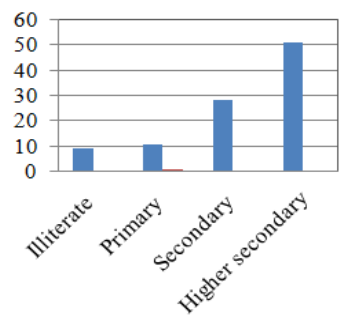

Figure 2. Percentage distribution of three selected attributes of mother's knowledge on vitamin A by education levels.

Table 3. Association of mother's occupation with knowledge on vitamin A rich foods in diet, Vitamin A deficiency disorder curable and Include green leafy vegetable and yellow fruits in diet $(2011, n=121)$.

\begin{tabular}{lllll}
\hline \multirow{2}{*}{ Variables with categories } & & \multicolumn{3}{c}{ Mothers' occupation } \\
\cline { 3 - 5 } & & $\begin{array}{l}\text { House } \\
\text { wife }\end{array}$ & $\begin{array}{l}\text { Service } \\
\text { holder }\end{array}$ & $\begin{array}{l}\text { Labourer } \\
\text { and others }\end{array}$ \\
\hline Vitamin A rich foods in & Yes & 56 & 52 & 13 \\
diet* & No & 0 & 0 & 0 \\
Vitamin A deficiency & Yes & 54 & 52 & 4 \\
disorder curable* & No & 2 & 0 & 9 \\
$\begin{array}{l}\text { Include green leafy } \\
\text { vegetable and yellow }\end{array}$ & Yes & 56 & 52 & 12 \\
fruits in diet* & No & 0 & 0 & 1 \\
\hline
\end{tabular}

$* \mathrm{p}<0.01$
Table 3 presents the association of mother's occupations with three selected significant factors such as mother's knowledge on vitamin A rich foods in diet, Vitamin A deficiency disorder curable and Include green leafy vegetable and yellow fruits in diet. Results demonstrate that there is a significant relationship between the mother's occupations and knowledge on vitamin A rich foods in diet. All the mothers with different occupations had knowledge on vitamin A rich foods in diet (see, Fig. 3). In addition, out of 56 housewife mothers only 2 mothers had no knowledge on VADD curability. Although all of the service holder mothers had knowledge on VADD issue, 
about $7.4 \%$ of mothers in the laborers and others groups of workforce had not have such knowledge. Similarly, all housewife and service holder mothers had awareness to include green leafy vegetable and yellow fruits in everyday diet, but only $0.8 \%$ of mothers in the category of laborers and others groups had no knowledge on such vitamin A supplements diet.
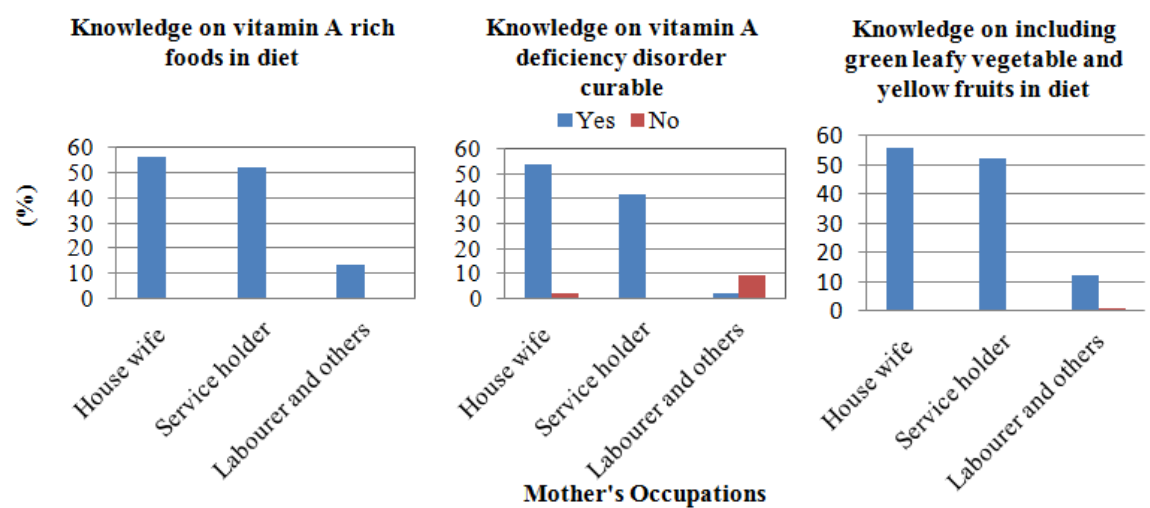

Figure 3. Percentage distribution of three selected attributes of mother's knowledge on vitamin A by occupations.

The family income variable also shows significant correlations with mother's knowledge on vitamin A rich foods in diet, Vitamin A deficiency disorder curable and Include green leafy vegetable and yellow fruits in diet (Table 4). Results reveal that all mothers with different monthly family income had knowledge on vitamin A rich foods and incorporate green leafy vegetable and yellow fruits in diet. Moreover, a fairly mixed result is observed for the knowledge on VADD curable. In particular, a significantly high percentage (about $5.8 \%$ of mothers)had no knowledge on VADD curability for family income less than 8001 Rupees, per month, and nearly $1.7 \%$ mothers had no awareness of this issue for monthly family income of 8001-10000 Rupees as well as more (see, Fig. 4).
Table 4. Association of monthly family income with knowledge on vitamin A rich foods in diet, Vitamin A deficiency disorder curable and Include green leafy vegetable and yellow fruits in diet $(2011, n=121)$.

\begin{tabular}{lllll}
\hline & & \multicolumn{3}{c}{ Family income per month(Rs) } \\
\cline { 3 - 5 } Variables with categories & & $<\mathbf{8 0 0 1}$ & $\mathbf{8 0 0 1 -}$ & \multicolumn{1}{c}{$\mathbf{1 0 0 0 0}$} \\
& & & $\mathbf{1 0 0 0 0}$ \\
\hline Vitamin A rich foods in & Yes & 20 & 22 & 79 \\
diet* $_{\text {Vitamin A deficiency }}$ & No & 0 & 0 & 0 \\
disorder curable* & Yes & 13 & 20 & 77 \\
Include green leafy & No & 7 & 2 & 2 \\
vegetable and yellow fruits & Yes & 19 & 22 & 79 \\
in diet* & No & 1 & 0 & 0 \\
\hline
\end{tabular}

${ }^{*} \mathrm{p}<0.05$
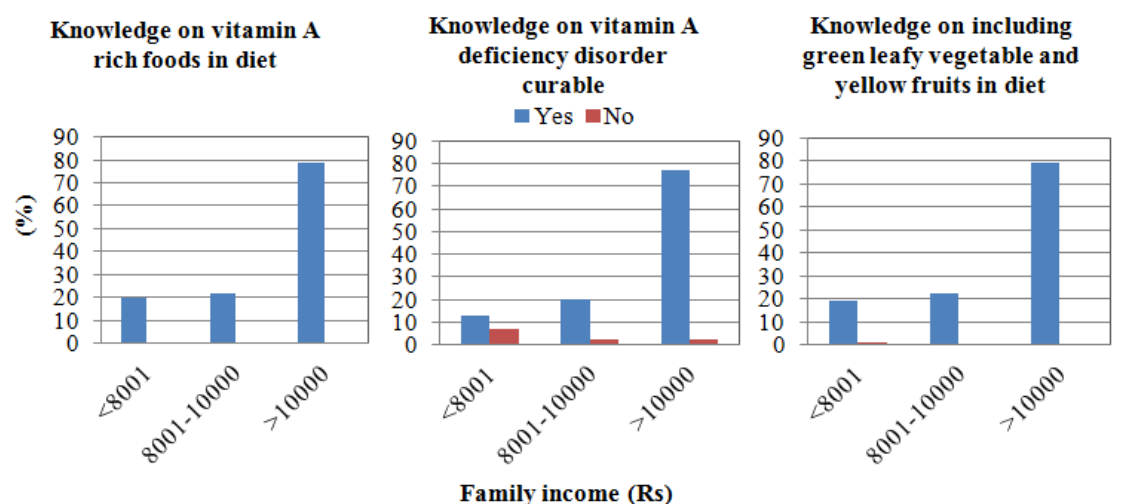

Figure 4. Percentage distribution of three selected attributes of mother's knowledge on vitamin A by monthly family income (Rs).

\section{Discussions and Conclusions}

This study has attempted to find out the relationships of several selected factors and the knowledge on vitamin A rich foods among mothers of preschool children in Nepal. Findings reveal that about $42.9 \%$ of mothers were in age group 28-32which was also the main child bearing age. Most of the mothers were Hindus because Nepal is a Hindu dominated country. Out of the 121 sampled mothers, $51.2 \%$ mothers had higher secondary education level, $9.1 \%$ of them were illiterate and the rest of the mothers belonged to education level from primary to secondary level. But the important part of the level of knowledge was $90.9 \%$ of the mothers were aware of vitamin A rich foods. Almost two-third of mothers lived in nuclear and 33.1\% mothers were lived in a joint family. With regard to the work status, 
approximately $46.3 \%$ mothers were house wife, $43 \%$ were service holder and $2.5 \%$ were laborers and others categories. When economic status was evaluated it was found that $65.3 \%$ of the mothers had monthly family income above 10,000Rupees, $16.5 \%$ mothers had monthly family income less than 8001 Rupees, and $18.2 \%$ of the mothers had monthly family income range between 800110000 Rupees.

Findings for the attitude of motherson vitamin A rich foods have illustrated that about $90.9 \%$ of the respondents grew vitamin A rich foods in their kitchen gardens and took it in their daily meal as diet. But a study carried out in Dominica Republic people showed that they grew vitamin a rich foods in their gardens only to provide a financial benefit for the family (Mills et al., 2007). It means awareness about VADD is more in Nepal than Dominica Republic. Besides this, attitude towards giving vitamin A rich foods to the children was seen to be quite remarkable. About $95.9 \%$ gave vitamin A rich foods to their children whereas in a study in India (Semba et al., 2010), it was seen that they grow more food grains than vitamin A rich foods to contain a food prices. As a result $11.4 \%$ children mortality was reported due to lack of vitamin A.

Moreover, about $93.4 \%$ mothers attend health centre with their children vitamin A supplementation campaign and $6.6 \%$ of them were not aware about VADD and did not attend health center. It clearly showed that awareness of mothers is quite appropriate regarding vitamin A deficiency as well as its prevention. Moreover, about $78.5 \%$ mothers knew about the first visible symptoms of vitamin A deficiency disorder, $94.7 \%$ mothers knew about night blindness and there were no women and children suffered from night blindness in the study area. However, a study (Arlappa et al, 2008) conducted in India showed that 1.1\% children had night blindness. Another study (Asrat et al., 2002) in Ethiopia also showed that $7.2 \%$ children suffered from night blindness. Hence it is clear that mothers of preschool children in Nepal are more conscious about the health of the children in relation to vitamin A deficiency, compare to some other developing countries.

The research has also demonstrated that more than $90.9 \%$ of the children liked to take Dark Green Leafy Vegetables (DGLV) which are very good sources of vitamin A. But a study which was conducted in Mumbai, India (Kothari et al., 2001) illustrated that $13.8 \%$ of mothers in urban slums area didn't give green leafy vegetable to their children as well as $23.1 \%$ of the children did not like to eat DGLV. Though the place are not same and culturally a little different but still awareness on vitamin A rich foods in Nepal is more than Indian situation.

In conclusions, like many other under developed and developing countries in the south and south-east Asia and in Africa the vitamin A deficiency disorder is a major public health problem in Nepal. Vitamin A deficiency was found to increase both childhood morbidity and mortality. As socio-economic status, education level and occupations are directly influencing the level of awareness and practice of consuming vitamin A rich foods, efforts from the Government and the local and international NGOs are required to improve such public health conditions in Nepal. Also effort are required to grow vitamin A rich foods, improve income, education, living condition, nutritional status and create awareness about its side effects of not consuming green leafy vegetables and yellow fruits etc, through the participation of the society to protect the VADD and its consequences in the bulk population of the nation.In addition, awareness of the mass population on VADD and vitamin A rich foods as well as its preventive measures should be created by government and intersartorial efforts. Awareness among women particularly those who are under privileged should be augmented by different programs like local health campaign, mass media, health education. Rational efforts by the policy makers can be taken into full account to improve socio-economic status, work participations and education level for all eligible citizens. A particular emphasis is required to significantly enhance women education and empowerment through effective social policies. Future research will explore such an objective by collecting new data from Nepal and neighboring countries.

\section{References}

[1] ACC/SCN. (1997), Third Report on the World Nutrition Situation. ACC/SCN, Geneva.

[2] Arlappa, N., Laxmaiah, A., Balakrishna, N., Harikumar, R. andBrahmam, G.N.V. (2008), Clinical and sub-clinical vitamin A deficiency among rural pre-school children of Maharashtra, India, 35(6): 606-614.

[3] Asrat, Y.T., Omwega, A.M., and Muita, J.W. (2002), Prevalence of vitamin A deficiency among pre-school and school-aged children in Arssi Zone, Ethiopia. East African Medical Journal, 79(7): 355-9.

[4] Bloem, M.W., Matzger, H. and Huq, N. (1995), Vitamin A deficiency among women in the reproductive years: an ignored problem, In: Two Decades of Progress: Linking Knowledge to Action. Report of the XVI International Vitamin A Consultative Group Meeting, Chiang Rai, Thailand, Washington DC, p. 78.

[5] Christian, P., West, J.K.P., Khatry, S.K., Katz, J., Shrestha, S.R., Pradhan, E.K., LeClerq, S.C. and Pokhrel, R.P. (1998b), Night blindness of pregnancy in rural Nepalnutritional and health risks, International Journal of Epidemiology, 27(2): 231-237.

[6] de Pee, S., West, C.E., Karyadi, M.D. and Hautvast, J.G. (1995), Lack of improvement in vitamin A status with increased consumption of dark-green leafy vegetables, Lancet, 346 (8967): 75-81.

[7] James, P., Norum, R.K., Smitasiri, S., Swaminathan, S.M., Tagwireyi, J., Uauy, R. and Haq, M (2000), Ending malnutrition by 2020: An agenda for change in the millennium, Final Report to the $\mathrm{ACC} / \mathrm{SCN}$ by the Commission on the Nutrition Challenges of the 21 st Century, UNSCN/ACC/SCN, Geneva, pp. 1-112. 
[8] Kassaye, T., Receveur, O., John, T. and Becklake, M.R. (2001), Prevalence of vitamin A deficiency among preschool and school-aged children in Arssi Zone, Ethiopia, Bulletin of the World Health Organization, 79(3): 415-422.

[9] Katz, J., Khatri, S,K., West, K.P., Humphrey, J.H., Leclerq, s.C., Pradhan, E.K., Pokhrel, R.P. and Sommer, A. (1995), Night blindness is prevalent during pregnancy and lactation in rural Nepal. The journal of Nutrition, 125(10): 2122-2127.

[10] Kothari, G., Bhattacharjee, L. and Marathe, M. (2001), Food acceptance and selection: Activities for promoting provitamin A foods among young children in urban slums, Community Eye Health, 14(37): 11-12.

[11] Megabiaw, B. and Rahman, A. (2013), Prevalence and determinants of chronic malnutrition among under-5 children in Ethiopia. International Journal of Child Health and Nutrition, 2(3): 230-236.

[12] Mills J.P., Mills, T.A. and Reicks, M. (2007), Caregiver knowledge, attitudes and practices regarding vitamin A intake by Dominican children, Maternal and Child Nutrition, 3(1): 58-68.

[13] NDHS. (2011), Nepal Demographic and Health Survey, Ministry of Health and Population, Government of Nepal, Kathmandu.

[14] Rahman, A. and Biswas, S.C. (2009), Nutritional status of under-5 children in Bangladesh, South Asian Journal of Population and Health 2(1), pp. 1-11.

[15] Rahman, A. and Chowdhury, S. (2007), Determinants of chronic malnutrition among preschool children in Bangladesh, Journal of Biosocial Science, 39(2), pp.161173.

[16] Rahman, A. and Harding, A. (2011), Social and health costs of tobacco smoking in Australia: Level, trend and determinants, International Journal of Statistics and Systems, 6(4), pp. 375-387.

[17] Rahman, A. and Harding, A. (2013), Prevalence of overweight and obesity epidemic in Australia: some causes and consequences, JP Journal of Biostatistics, 10(1), pp. 3148.

[18] Rahman, A. and Harding, A. (2014), Spatial analysis of housing stress estimation in Australia with statistical validation, Australasian Journal of Regional Studies 20(3), pp. (in press).
[19] Rahman, A. and Kuddus, A. (2014), A new model to study on physical behaviour among susceptible infective removal population, Far East Journal of Theoretical Statistics, (in press).

[20] Rahman, A., Chowdhury, S., and Hossain, D. (2009), Acute malnutrition in Bangladeshi children: levels and determinants, Asia-Pacific Journal of Public Health, 21(3), pp. 294-302.

[21] Rahman, A., Chowdhury, S., Karim, A. and Ahmed, S. (2008), Factors associated with nutritional status of children in Bangladesh: A multivariate analysis, Demography India, 37(1), pp. 95-109.

[22] Rahman, A., Harding, A., Tanton, R. and Liu, S. (2010), Methodological issues in spatial microsimulation modelling for small area estimation, The International Journal of Microsimulation 3(2), pp. 3-22.

[23] Rahman, A., Harding, A., Tanton, R. and Liu, S. (2013), Simulating the characteristics of populations at the small area level: New validation techniques for a spatial microsimulation model in Australia, Computational Statistics \& Data Analysis, 57(1), pp. 149-165.

[24] Sally, B., Gormez, A., Rahman, A., and colleagues (2012), Jurisdictional, socioeconomic and gender inequalities in child health and development: Analysis of a national census of 5 year olds in Australia, BMJ Open, 2(5):e001075, pp. 115.

[25] Semba, R.D., de Pee, S., Sun, K, Bloem, M.W. andRaju, V.K.( 2010), The role of expanded coverage of the national vitamin A program in preventing morbidity and mortality among preschool children in India, The Journal of Nutrition, 140(1): 208s-212s.

[26] UNICEF. (1997), Malnutrition in South Asia: A regional profile. Kathmandu: UNICEF - Regional Office of South Asia, p. 189 (ROSA Publication no: 5)

[27] WHO. (1996), Indicators for assessing vitamin A deficiency and their application in monitoring and evaluating intervention programmes, WHO/NUT/96.10, World Health Organization, Geneva.

[28] WHO. (2002), The world health report 2002: Reducing risks, promoting healthy life, WHO publication, Geneva, p 55. 